\title{
KAJIAN RUANG PUBLIK KOTA ANTARA AKTIVITAS DAN KETERBATASAN
}

\author{
Dedi Hantono \\ Arsitektur Universitas Muhammadiyah Jakarta \\ dedihantono@ftumj.ac.id
}

\author{
Yuanita F.D. Sidabutar \\ Universitas Batam \\ yuanitasidabutar@gmail.com
}

Ully Irma Maulina Hanafiah

Telkom University

ullyrmaulinafia@telkomuniversity.ac.id

\begin{abstract}
Abstrak
Ruang esensinya adalah tempat manusia hidup dan beraktivitas. Namun tidak semua aktivitas dapat terakomodir karena setiap ruang dibatasi dengan fungsinya masing-masing. Bagi ruang pribadi keterbatasan ruang tersebut merupakan karakteristik utama bagi ruang itu sendiri sedangkan pada ruang publik yang memiliki berbagai macam aktivitas harus dapat menampung berbagai aktivitas di dalamnya. Untuk itulah perlu dilakukan kajian mengenai ruang publik terhadap permasalahan keterbatasan ruang yang sering ditemui. Tulisan ini menggunakan metode kualitatif dengan melakukan pendekatan kajian literatur. Ada beberapa literatur yang diambil dari beberapa ahli serta beberapa hasil penelitian dalam artikel jurnal untuk mendukung teori dan melihat kenyataan di lapangan. Pada akhir tulisan diambil suatu kesimpulan bahwa keterbatasan ruang publik terhadap berbagai macam aktivitas yang berlangsung di dalamnya dengan terbentuknya ruang bersama baik secara permanen maupun bergantian (waktu tertentu).
\end{abstract}

Kata-kata Kunci: arsitektur, ruang publik, aktivitas, ruang bersama

\section{URBAN PUBLIC SPACE STUDIES BETWEEN ACTIVITIES AND LIMITATIONS}

\begin{abstract}
The essence of space is a place where humans live and doing their activities. But not all activities can be accommodated because space is limited by their functions. For private space, space limitations are the main characteristics for space itself, while in public spaces that have various kinds of activities must be able to accommodate multiple activities in it. For this reason, a study of public space needs to be done on the problems of space limitations that are often encountered. This paper uses qualitative methods by conducting a literature review approach. There is some literature taken from several experts and several research results in the journal for support the theory and see the reality in the field. At the end of the writing, it was concluded that the limitations of the public space for various kinds of activities take place in it with the formation of shared spaces both permanently and alternately (certain times).
\end{abstract}

Keywords: architecture, public space, activity, share space 


\section{Pendahuluan}

Dari dulu hingga sekarang kota selalu menarik minat sebagai tempat usaha, bekerja, bahkan bertempat tinggal karena kota memiliki sarana dan prasarana yang dapat memenuhi segala aktivitas yang dibutuhkan. Hal ini yang menjadikan mobilitas manusia dari desa/pinggiran kota menuju kota hampir tidak bisa dibendung lagi. Pertambahan jumlah penduduk dibanding dengan volume ruang yang bersifat tetap menjadikan ruang sebagai permasalahan utama kota.

Ruang publik sebagai elemen utama kota juga memiliki permasalahan berupa keterbatasan ruang. Apalagi ruang publik merupakan ruang yang dapat diakses oleh siapa saja dengan berbagai aktivitas yang sangat beragam, seperti: olahraga, seni, rekreasi, demonstrasi, perdagangan, transit, dan lain-lain. Selain dimanfaatkan oleh warga kotanya sendiri, ruang publik tersebut sering juga digunakan oleh warga dari kota lain sehingga menambah beban ruang yang membawa dampak pada ruang publik kota.

Banyak ruang publik yang berubah fungsi untuk dapat menampung berbagai aktivitas yang dibutuhkan sebagai upaya "solusi" terhadap permasalahan keterbatasan ruang publik kota. Trotoar sebagai bagian dari ruang publik kota yang berfungsi sebagai jalur sirkulasi sering juga dijadikan tempat berjualan bagi pedagang kaki lima. Pada umumnya mereka berjualan dengan berpindahpindah tempat (Salomon-Ayeh, King, \& Decardi-Nelson, 2011). Banyak juga para pekerja seni yang menafaatkan ruang publik dalam menunjukkan bakatnya sekaligus menggantungkan kelangsungan hidupnya dalam ruang publik kota dengan mengharapkan imbalan dari pertunjukan mereka (Olesen \& Lassen, 2012). Namun apakah perubahan fungsi ruang tersebut benar-benar menjadi jawaban permasalahan terhadap keterbatasan ruang publik yang ada? Selain perubahan fungsi, apalagi fenomena yang terjadi pada ruang publik dalam mengatasi keterbatasan ruang tersebut? Untuk itu perlu dilakukan kajian mengenai fenomena yang terjadi dalam ruang publik kota. Dari kajian yang dilakukan diharapkan dapat memberikan gambaran terhadap apa saja yang terjadi dalam ruang publik kota dan memberikan jawaban terhadap permasalahan sehingga kajian yang dilakukan ini dapat membantu dalam rancangan maupun perbaikan ruang publik kota yang lebih baik lagi.

\section{Kajian Pustaka}

Dalam defenisi yang sederhana ruang publik adalah ruang terbuka yang berada di luar bangunan, diantaranya: jalan, lapangan, taman kota, dan lain-lain (S. Carr, Francis, Rivlin, \& Stone, 1992). Ruang publik dapat mengakomodasi berbagai aktivitas masyarakat secara individu maupun berkelompok. (Mulyandari, 2011).

Rob Krier (1979) mengungkapkan bahwa ruang publik adalah ruang yang terbentuk diantara massa bangunan (Krier, 1979). Sejalan dengan itu, Hakim (2003) menjelaskan pula bahwa ruang publik memiliki fungsi sebagai sarana mobilitas manusia untuk bergerak dari satu bangunan ke bangunan lain atau satu tempat ke tempat lainnya (Hakim \& Utomo, 2003).

Hakim (2003) menjelaskan bahwa ruang publik memiliki 2 fungsi utama, yaitu: fungsi sosial dan fungsi ekologis. Dalam fungsinya sebagai fungsi sosial, ruang publik merupakan wadah bagi berbagai aktivitas, diantaranya: bermain, olahraga, komunikasi, keserasian, keindahan lingkungan, pembatas antar massa bangunan, dan lain-lain. Dan sebagai fungsi ekologis ruang publik berperan sebagai penyegar udara, penyerapan air hujan, pemelihara ekosistem, pelembut arsitektur, dan lainlain. Apabila ruang publik digunakan sesuai dengan fungsinya maka ruang ini juga dapat menjadi bagian elemen estetika dari ruang kota. Hal ini bisa didapat dari elemen dan aktivitas yang ada di ruang publik itu sendiri (Hantono, 2017).

Dari beberapa literatur di atas cukup jelas bahwa ruang publik adalah ruang yang bisa diakses oleh siapa saja sehingga ruang publik menjadi ruang milik bagi seluruh kalangan tanpa ada batasan waktu dan aktivitas. Sejalan dengan hal tersebut Athanassiou (2017) menjelaskan bahwa ruang publik tidak bisa dimiliki oleh siapa saja (Athanassiou, 2017). Namun kebebasan waktu dan aktivitas 
yang terjadi di dalam ruang publik dengan segala keterbatasan yang ada menjadi persoalan yang cukup berat bagi ruang kota.

\section{Metode Penelitian}

Tulisan yang memuat kajian literatur ini menggunakan metode penelitian kualitatif dengan pendekatan naratif yang didapat dari kajian literatur yang ada. Literatur utama diambil dari teori beberapa ahli mengenai arsitektur kota sedangkan literatur lainnya diambil dari beberapa artikel jurnal yang didapat dari penelitian yang sudah dilakukan. Literatur ini berfungsi untuk mendukung atau bahkan menyangkal teori yang sudah ada dengan melakukan analisis berupa kajian.

Dalam melakukan penelitian berupa kajian literatur ini sebaiknya menggunakan sumber primer yaitu berupa hasil penelitian orang lain yang dilakukan sendiri oleh penulisnya, seperti: buku, skripsi, tesis, disertasi, laporan penelitian, dan lain-lain karena lebih otentik dibandingkan dengan sumber sekunder. Namun jika diperlukan maka sumber sekunder juga bisa digunakan, seperti: ensiklopedi, kamus, indeks, textbooks, dan lain-lain.

Agar kasus penelitiannya tidak ketinggalan zaman dan tetap update terhadap kondisi yang ada maka literatur yang digunakan jangan terlalu lama, maksimal lebih kurang 10 tahun khususnya literatur yang berasal dari artikel jurnal penelitian. Literatur yang terlalu lama bisa menhasilkan penelitian yang tidak optimal bahkan sudah kadaluarsa karena ada teori atau rujukan yang lebih baru.

Langkah-langkah yang dilakukan dalam kajian literatur yaitu:

1. Inventarisasi litertur.

2. Deskripsi literatur.

3. Perbandingan literatur.

Pada akhir tulisan dibuat kesimpulan mengenai fenomena yang terjadi dalam ruang terbuka publik. Apakah sesuai dengan teori yang ada atau bahkan bertentangan. Jika bertentangan maka perlu dilakukan penelitian yang lebih mendalam untuk mendapatkan mendapatkan jawaban penelitian yang sudah dilakukan.

\section{Hasil dan Pembahasan Ruang Publik}

Konflik yang terjadi di dalam ruang publik sudah mulai dirasakan pada penelitian Sudarisman (2017). Taman sebagai salah satu bagian dari ruang publik seharusnya memiliki fungsi keindahan untuk mencapai kenyamanan dan bisa diakses oleh siapa saja. Namun tidak seperti halnya yang terjadi pada Taman Tegalega di kota Bandung. Taman tersebut berubah fungsi menjadi ruang berjualan bagi Pedagang Kaki Lima (PKL). Tingkat sebaran ini bahkan sampai pada ruas trotoar dan ruang-ruang publik lain di sekitarnya. Walaupun perkembangan para PKL ini menimbulkan beragam persoalan bagi pengguna taman lainnya namun kehadiran PKL ini sudah menjadi kebutuhan bagi sebagian orang lainnya (Sudarisman, 2017).

Ruang publik yang memiliki keterbatasan pada kawasan dengan densitas yang tinggi menjadikan ruang publik digunakan dengan fungsi campuran (mix used). Terbentuklah kawasankawasan yang kompak namun semakin mudah dikases karena jaraknya yang semakin dekat (kompak). Hal ini tumbuh untuk menjaga daya tahan lingkungannya agar dapat bertahan (Hanafiah \& Asharsinyo, 2017).

Ruang jalan sebagai salah satu ruang publik kota yang bisa dinikmati dengan beragam aktivitas mengalami perubahan fungsi menjadi tempat pertunjukan jalanan. Dalam penelitian yang dilakukan di Bath-Inggris tersebut Simpson mendapati intervensi yang dilakukan para pemusik jalanan tersebut bersifat temporer dengan berbagi ruang dengan penikmat pertunjukan serta aktivitas lainnya (Simpson, 2011). 
Pemanfaatan ruang pada waktu tertentu juga terjadi pada ruang publik di area permukiman dan pertokoan di Tangerang Selatan. Pedagang kecil berjualan dengan berpindah-pindah tempat sesuai dengan tempat dan hari yang telah disepakati sebelumnya dengan waktu operasional jam 17.00 22.00 WIB (Rochimah \& Asriningpuri, 2018). Kasus yang serupa juga ditemui oleh Agustapraja (2018) dimana trotoar Alun-Alun Kota Malang berubah fungsi menjadi area berjualan pada waktu sore dan malam hari (Agustapraja, 2018).

Dalam penelitian Murtini \& Wahyuningrum (2017) ruang publik yang dipakai secara bersamaan dalam permukiman di Gang Baru Pecinan Semarang antara pedagang dan warga merupakan hasil kesepakatan mereka bersama yang sifatnya non-permanen. Para pedagang menempati sebagian halaman depan rumah penduduk dengan "imbalan" pedagang tersebut bersedia untuk membersihkan kembali halaman tersebut. Pasar ini hanya beroperasi hanya pada pagi hari (Murtini \& Wahyuningrum, 2017).

Konflik ruang bisa juga terjadi pada perancangan ruang yang tidak sesuai dengan standing pattern of behavior dengan beberapa fungsi dan berbagai karakter aktivitas yang berbeda. Demi mencapai efektifitas ruang dengan keterbatasan ruang yang ada dapat dilakukan upaya melalui penggunaan ruang yang bergantian (Santoso, Mustikawati, Suryasari, \& Titisari, 2016).

Tabel 1. Fenomena ruang publik pada beberapa penelitian

\begin{tabular}{|c|c|c|}
\hline \multirow{2}{*}{ Tulisan } & \multicolumn{2}{|c|}{ Pembagian Penggunaan Ruang Publik } \\
\hline & Ruang & Waktu \\
\hline Rochimah (2018) & $\begin{array}{l}\text { Pedagang menempati sebagian } \\
\text { halaman rumah orang, ruang } \\
\text { terbuka, atau deretan pertokoan. } \\
\text { Mereka juga selalu berpindah- } \\
\text { pindah tempat sesuai dengan } \\
\text { kesepakatan antar mereka }\end{array}$ & $\begin{array}{l}\text { Waktu operasional } 17.00- \\
20.00 \text { WIB }\end{array}$ \\
\hline Agustapraja (2018) & $\begin{array}{l}\text { Trotoar Alun-Alun Kota } \\
\text { Malang digunakan sebagai } \\
\text { ruang jualan bagi PKL }\end{array}$ & Sore dan malam hari \\
\hline $\begin{array}{l}\text { Hanafiah \& Asharsinyo } \\
(2017)\end{array}$ & $\begin{array}{l}\text { Penggunaan fungsi campuran } \\
\text { (mix used) }\end{array}$ & Permanen \\
\hline Murtini (2017) & $\begin{array}{l}\text { Pedagang menggunakan } \\
\text { sebagian dari halaman rumah } \\
\text { orang berdasarkan kesepakatan } \\
\text { antar mereka. }\end{array}$ & $\begin{array}{l}\text { Pasar hanya beroperasi pada } \\
\text { pagi hari saja. }\end{array}$ \\
\hline Sudarisman (2017) & $\begin{array}{l}\text { Perubahan fungsi taman } \\
\text { menjadi ruang berjualan bagi } \\
\text { PKL. Fenomena ini kemudian } \\
\text { berkembang pada trotoar dan } \\
\text { ruang publik lain yang ada di } \\
\text { sekitarnya }\end{array}$ & Permanen \\
\hline Santoso (2016) & $\begin{array}{l}\text { Mewadahi kegiatan yang } \\
\text { berbeda-beda karakternya }\end{array}$ & $\begin{array}{l}\text { Pada suatu kasus ruang } \\
\text { digunakan secara bergiliran }\end{array}$ \\
\hline Simpson (2011) & $\begin{array}{l}\text { Berbagi ruang pertunjukan } \\
\text { dengan aktivitas lain }\end{array}$ & o r o r s \\
\hline
\end{tabular}

Sumber: Hasil Analisis, 2018

Dari tabel di atas terlihat bahwa ruang publik bukan hanya mengenai ruang saja melainkan juga ada waktu yang juga menjadi elemen pembentuk ruang tersebut. Ruang bisa saja menjadi 
berbeda tergantung dari waktu yang terjadi di dalamnya. Selain aktivitas utama, aktivitas pendukung (activity support) juga memperkuat bentuk dan karakteristik ruang serta menjadikan fungsi dan aktivitas yang lebih spesifik (Liem \& Lake, 2018).

\section{Respon Terhadap Keterbatasan Ruang Publik}

Keberadaan ruang selalu berdampingan dengan ruang lain, ruang dalam dan ruang luar, ruang gelap dan ruang terang, ruang bawah dan ruang atas, dan sebagainya. Dalam konteks kegunaannya, ruang-ruang tersebut bisa dikatakan sebagai fungsi ruang. Sebelum wujud ruang tersebut ada ruang tersebut sudah memiliki batasan fungsi (space by design). Namun seiring waktu pemakaian dan aktivitas yang berkembang di dalamnya maka tak jarang pula ruang yang sudah terbentuk memiliki fungsi yang berbeda dari tujuan awal (design) bahkan ada penambahan fungsi. Semakin banyak aktivitas yang berlangsung di dalamnya semakin besar kemungkinan pemanfaatan atau fungsi ruang ini menjadi lebih komplek. Satu ruang yang dipakai dalam satu waktu yang sama atau berbeda menjadi ruang bersama bagi masyarakat yang memanfaatkannya. Hal inilah yang sering terjadi dalam ruang publik kota.

Ruang bersama merupakan ruang yang digunakan untuk interaksi antara sesama anggota suatu komunal secara bersama. Lingkungan permukiman sebagai wujud komunal tersebut terbentuk karena adanya proses pembentukan hunian yang dilandasi oleh pola aktivitas manusia dan pengaruh seting baik fisik maupun non fisik yang secara langsung mempengaruhi pola aktivitas dalam ruang (Rapoport, 1990).

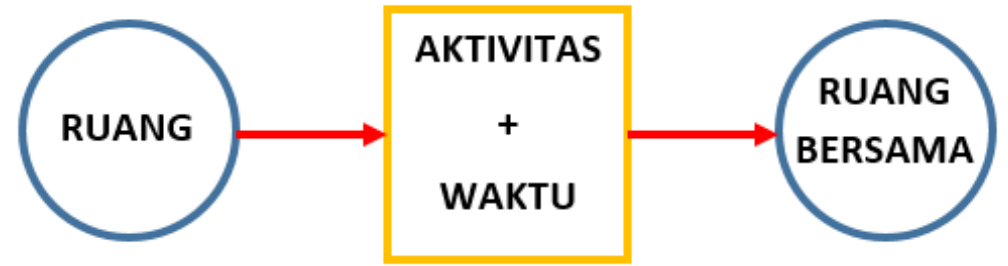

Gambar 1. Proses pembentukan ruang bersama

Sumber: Hasil Analisis, 2018

Ruang bersama juga dapat mempengaruhi interaksi antara pengguna ruang tersebut sebagaimana yang dikemukakan oleh Naceur Farida (2013). Beliau mempelajari bagaimana karakteristik ruang bersama terutama di ruang luar mempengaruhi interaksi antar warga pada suatu komplek perumahan. Dalam studinya, anak-anak dianggap menjadi sumber gangguan dan konflik di lingkungan mereka. Hal ini disebabkan kurangnya tempat bermain yang memadai dan kurangnya pengawasan orang tua selama anak-anak tersebut berada di ruang luar (Farida, 2013).

Dalam konteks ruang bersama, John Carr (2017) mengajukan pemahaman akan ruang fleksibel sebagai alternatif perencanaan ruang bersama perkotaan. Ruang fleksibel yang dimaksud untuk menawarkan bentuk penggunaan lahan yang yang dapat dikonfigurasi ulang, dapat berubah, dan tidak permanen (J. Carr \& Dionisio, 2017).

\section{Kesimpulan}

Ruang hadir dalam berbagai wacana dan bentuk termasuk dalam arsitektur. Di tengah geliatnya pembangunan di perkotaan, ruang adalah sesuatu barang langka yang selalu menjadi primadona tak peduli seberapa mahalnya harga ruang tersebut. Namun tidak semua ruang tersebut bisa dibeli walaupun dengan harga yang berani dibayar tinggi. Oleh beberapa sebab seperti untuk menjaga keseimbangan lingkungan, ruang untuk elemen estetika, mobilitas kota, fasilitas sosial/umum, atau ruang yang masih menunggu pembangunan sesuai dengan rencana kotanya maka sebagian ruang itu 
tetap tidak dijual atau dibiarkan sebagai ruang terbuka publik dimana siapa dan kapan saja dapat mengakses ruang tersebut.

Dalam penggunaanya terkadang terjadi begitu spontan dan tanpa rencana. Dalam suatu waktu bisa berlangsung begitu banyak aktivitas yang berlangsung di dalamnya baik yang sifatnya temporer maupun dalam waktu yang cukup lama. Dalam batasan tersebut penggunaan ruang pada ruang publik dilakukan dengan secara bersama-sama. Konsep penggunaan ruang bersama tersebut bisa dilakukan secara bersamaan (ruang) atau bisa juga secara bergantian (waktu).

Bentukan ruang bersama (share space) sebenarnya merupakan solusi bagi terbatasnya ruang publik yang tersedia. Namun ruang bersama ini pula yang memberi banyak permasalahan pada ruang kota karena sifatnya yang tidak terkendali dan tidak terencana. Untuk itu perlu dilakukan perencanaan dan pengawasan yang baik dalam pertumbuhan ruang bersama dalam ruang publik kota.

Namun karena keterbatasan waktu dan biaya penelitian ini masih dirasa jauh dari sempurna. Masih banyak bahasan dan kajian yang bisa diperdalam seperti bagaimana seting fisik terhadap fenomena yang terjadi, perilaku para pengguna terhadap pembentukan ruang publik yang baru sebagai respon dari keterbatasan ruang publik tersebut, serta masih banyak lagi kajian yang bisa dilakukan. Untuk itu diharapkan penulis memiliki kesempatan berikutnya agar dapat meneliti lebih mendalam lagi. Atau diharapkan tulisan ini bisa menjadi acuan atau referensi bagi pembaca untuk melanjutkan penelitian berikutnya.

\section{Daftar Pustaka}

Agustapraja, H. R. (2018). Studi Pemetaan Perilaku (Behavioral Mapping) Pejalan Kaki Pada Pedesterian Alun-Alun Kota Lamongan. Civilla, 3(1), 134-139. https://doi.org/https://doi.org/10.30736/cvl.v3i1. 220

Athanassiou, E. (2017). The Hybrid Landscape Of Public Space In Thessaloniki In The Context Of Crisis. Landscape Research, 42(7), 782-794. https://doi.org/10.1080/01426397.2017.1372399

Carr, J., \& Dionisio, M. R. (2017). Flexible Spaces as a Third Way Forward for Planning Urban Shared Spaces. In Cities (pp. 73-82). Elsevier. https://doi.org/10.1016/j.cities.2017.06.009

Carr, S., Francis, M., Rivlin, L. G., \& Stone, A. M. (1992). Public Space. New York: Cambridge University Press.

Farida, N. (2013). Effect of Outdoor Shared Spaces on Social Interraction in a Housing Estate in Algeria. Frontiers of Architectural Research, 2, 457-467. https://doi.org/10.1016/j.foar.2013.09.002

Hakim, R., \& Utomo, H. (2003). Komponen Perancangan Arsitektur Lansekap: Prinsip-Unsur dan Aplikasi Desain. Jakarta: Penerbit Bumi Aksara.

Hanafiah, U. I. M., \& Asharsinyo, D. F. (2017). Redefenisi Ruang Publik Pada Kampung Kreatif Pasundan. Studi Kasus: Koridor Tepian Sungai Cikapundung, RT 02 RW 04, Kelurahan Balonggede, Kecamatan Regol, Kota Bandung, Jawa Barat. Idealog, 2(2), 124-137. https://doi.org/10.25124/idealog.v2i2.1220

Hantono, D. (2017). Pengaruh Ruang Publik Terhadap
Kualitas Visual Jalan Kali Besar Jakarta. Arsitektura, 15(2), 532-540. https://doi.org/10.20961/arst.v15i2.15114

Krier, R. (1979). Urban Space. New York: Rizzoli.

Liem, Y., \& Lake, R. C. (2018). Pemaknaan Ruang Terbuka Publik Taman Nostalgia Kota Kupang. Arteks, 2(2), 149-158. https://doi.org/10.30822/artk.v2i2.150

Mulyandari, H. (2011). Pengantar Arsitektur Kota. (Oktaviani HS, Ed.) (1st ed.). Yogyakarta: Penerbit Andi.

Murtini, T. W., \& Wahyuningrum, S. H. (2017). Penggunaan Ruas Jalan Sebagai Pasar Tradisional Di Gang Baru Pecinan, Semarang. Modul, 17(1), 17-21. Retrieved from https://ejournal.undip.ac.id/index.php/modul/arti cle/view/17246/12396

Olesen, M., \& Lassen, C. (2012). Restricted Mobilities: Access to, and Activities in, Public and Private Spaces. International Planning Studies, 17(3), 215-232. https://doi.org/10.1080/13563475.2012.704755

Rapoport, A. (1990). The Meaning of the Built Environment: A Nonverbal Communication Approach (1st ed.). Arizona: University of Arizona Press.

Rochimah, E., \& Asriningpuri, H. (2018). Adaptasi Perilaku Pedagang Bazar Dalam Teritori Ruang Dagang. Nalars, 17(1), 21-28. https://doi.org/10.24853/nalars.17.1.21-28

Salomon-Ayeh, B. E., King, R. S., \& Decardi-Nelson, I. (2011). Street Vending and The Use of Urban Public Space in Kumasi, Ghana. Surveyor, 4(1), 20-31. Retrieved from 
http://dspace.knust.edu.gh/bitstream/123456789/ 3423/1/Surveyor Journal 3.pdf

Santoso, J. T., Mustikawati, T., Suryasari, N., \& Titisari, E. Y. (2016). Pola Aktivitas Wisata Belanja dI Kampung Wisata Keramik Dinoyo, Malang. Tesa Arsitektur, 14(1), 1. https://doi.org/10.24167/tes.v14i1.560

Simpson, P. (2011). Street Performance And The City: Public Space, Sociality, And Intervening In The Everyday. Space and Culture, XX(X), 1-16. https://doi.org/10.1177/1206331211412270

Sudarisman, I. (2017). Kajian Pedagang Kaki Lima Di Taman Tegalega, Bandung, Jawa Barat. Arsir , 1(2), 161-174. Retrieved from http://jurnal.umpalembang.ac.id/arsir/article/view/867/769 